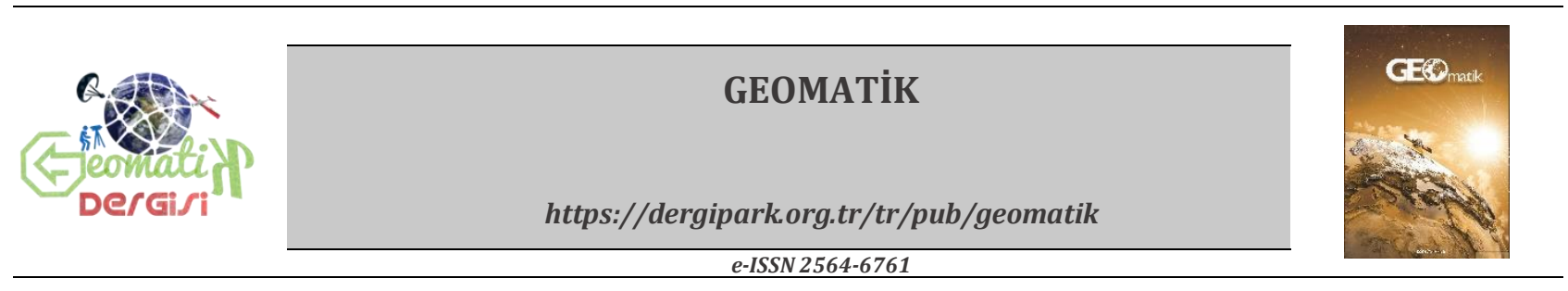

\title{
Yeraltı Suyu Kaynaklarının Uzaktan Algılama ve CBS Teknikleri Kullanarak Modellenmesine Yönelik bir Yaklaşım: Kırkgöz Havzası (Antalya)
}

\author{
Mustafa Kaynarca', Nusret Demir*2, Bekir Taner San ${ }^{3}$ \\ ${ }^{1}$ Antalya Büyükşehir Belediyesi Su ve Atık Su İdaresi (ASAT) Genel Müdürlüğü, Antalya, Türkiye \\ ${ }^{2}$ Akdeniz Üniversitesi, Fen Fakültesi, Uzay Bilimleri ve Teknolojileri Bölümü, Antalya, Türkiye \\ ${ }^{3}$ Akdeniz Üniversitesi, Mühendislik Fakültesi, Jeoloji Mühendisliği Bölümü, Antalya, Türkiye
}

Anahtar Kelimeler

Yeraltı suyu

Modelleme

Sinıflandırma

\begin{abstract}
ÖZ
Ülkemizin su potansiyelinin büyük çoğunluğu yer altı suyundan oluşmaktadır. Antalya da Türkiye'nin toplam yeraltı suyu potansiyelinin \%5.6' sına sahiptir. Antalya'da içme suyu ihtiyacının büyük çoğunluğu yer altı suyundan karşılanmaktadır. Bu çalışmada içme suyunun karşılandığı alanlarda, yer altı suyunun özellikleri belirlenmiştir. Test alanı olarak önemli içme suyu kaynaklarından Kırkgözler seçilmiştir. Burada mekânsal veriler (jeoloji, arazi modeli, kuyular) kullanılmıș, su seviyesi ve verimlilik değerlerini içeren tematik haritalar üretilmiștir. Uydu görüntüsü olarak Sentinel-2 görüntüleri kullanılıp karar vektör makinaları yöntemi ile sınıflandırılarak arazi kullanım özellikleri belirlenmiștir. Bu çalışma (Kaynarca vd. 2019) 'nın genişletilmiş versiyonudur.
\end{abstract}

\section{An Approach for Modeling of Ground Water Sources Using Remote Sensing and GIS Techniques: Kırkgoz Catchment (Antalya)}

Keywords

Groundwater

Modelling

Classification

\begin{abstract}
The majority of Turkey's water potential consists of groundwater. Antalya has a groundwater potential with $5.6 \%$ of the whole country. In Antalya, the majority of tap water is supplied from needs from groundwater. In this study, the properties of groundwater are determined at the locations where the need of tap water is provided. Kırkgözler is selected as test area which is one of important location for the tap water supply. Geospatial datasets have been used (geological information, terrain model, well points) and groundwater level and productivity measurements are used. Sentinel-2 images have been used as satellite imagery, and support vector machine method is used for determination of the land-use. This is study is an extended version of (Kaynarca et al. 2019)
\end{abstract}

Kaynarca, M, Demir, N, San, B. (2020) Yeraltı Suyu Kaynaklarının Uzaktan Algılama ve CBS Teknikleri Kullanarak Modellenmesine Yönelik bir Yaklașım: Kırkgöz Havzası (Antalya). Geomatik 5(3), 241-245, DOI: 10.29128/geomatik.649221 


\section{GíRiş}

Uzaktan algılama ve coğrafi bilgi sistemleri (CBS) tarım (Demir vd. 2018), ekoloji (Selim ve Demir, 2018), ulaşım, jeoloji (Orhan, Kırtıloğlu, \& Yakar, 2020), planlama gibi bir çok alanda ve disiplinde kullanılmaktadır. Özellikle son on yıllık zaman diliminde, uzaktan algılama ve CBS entegrasyonu birçok çalışmada bir arada yer almaktadır. Web of Science verilerine göre; son 20 yıllık dönemde 1998 yılında 2756, 2008 yılında 6270, 2018 yılında 14869 adet bilimsel yayın uzaktan algılama ve CBS konularında yapılmıştır. Hemen hemen tüm çok disiplinli çalışmalarda, planlama aşamalarında kullanılır hale gelmiştir.

İnsanoğlu için en önemli yaşamsal kaynakların başında su gelmektedir. Temiz ve kullanılabilir su kaynakları yaşamsal nitelikte olup kentimizde kullanılan suyun \%98 yeraltı suyundan temin edilmektedir (DSİ, 2018). Bu kaynak içme suyu olarak kullanılmasının yanı sıra tarımsal sulamada da yoğun olarak kullanılmaktadır. Yer altı sularından maksimum fayda için davranışlarının bilinmesi ve yeryüzündeki alan kullanımları ile ilişkisi yer altı suyunun iyi yönetilmesi açısından önem arz etmektedir (Hökelekli \& Yılmaz, 2010).

Literatüre bakıldığı zaman yeraltı suları ve barajlarla ile ilgili bazı çalışmalar yapılmıştır (Erener \& Sarp, 2017) . Yapılan bir çalışmada Harran ovasının bir bölümünde bir bölümünde yeraltı suyu seviyeleri ve verimlilik düzeyleri araştırılmış ve haritalandırılmıştır (Çelik, 2017). Afyon Akarçay havzasının yeraltı suyu modellemesi Hökelekli ve Yılmaz (2010) tarafından yapılmıştır. Polemio (2016) tarafından yapılan çalışmada İtalya'nın güney bölgesinin akifer modellemesi ve yeraltı suyu izlenmesi çalışması yapılmıştır. Kunianski (2016) tarafından Florida'da yapılan çalışmada jeolojik olarak Karstik yapıdaki bu bölgedeki kuyu verileri kullanılarak akifer modeli ve akış yönleri bulunmaya çalışılmıştır. San ve Ulusar (2018) tarafindan yapılan çalışmada ise uydu görüntüleri ve hava fotoğraflarından otomatik çıkarılan tarihsel kıyı çizgileri ile birlikte mevcut durumdaki kıyı çizgisi çıkarılmıştır. Sınıflandırma ile ilgili birçok çalışma yer almakta olup Kavzoğlu vd. (2015) tarafından yapılan çalışmada destek vektör makineleri yönteminin kentsel ve kırsal alan sınıflandırmasında yüksek doğruluk ile sinıflandırma yapabildiği belirlenmiștir.

$\mathrm{Bu}$ çalışmada, nüfusu 1,5 milyonu bulan Antalya ili merkez ilçelerinin (Muratpaşa, Kepez, Konyaaltı, Aksu, Döşemealtı) ana içme ve kullanma suyu sistemini içinde barındıran Kırgözler yeraltı suyu kaynağı seçilmiştir. Bu sistem ile onunla ilintili olan yüzey sınıfları ve alan kullanımları da değerlendirilmiştir. Karstik bir jeolojik yapıya sahip olan bu sistemde ağırlıklı olarak aynı litolojik birim, litolojik farklılıklar nedeniyle ortaya çıkabilecek farklılıklar değerlendirmeye katılmamıştır. Çalışmada ele alınan temel litolojik birim, Antalya
Şehir merkezini de içeren Kuvaterner olan yaşlı Traverten , Antalya Tufasıdır.

$\mathrm{Bu}$ çalışmanın amacı bu formasyon üzerinde yer alan yeraltı suyu kuyuları verileri kullanılarak interpolasyon yardımı ile yeraltı suyu statik, dinamik ve kuyu verimlilik tematik haritalarının oluşturulmasıdır. Çalışmada ayrıca yeraltı suyu statik ve dinamik seviyeleri arazi modeline göre 3 boyutlu görselleştirme yapılarak yeraltı suyu seviyesi ve kuyular arazi modeline göre gösterilmesi hedeflenmiştir. Çalışmanın yapıldığı traverten formasyonunda arazi örtüsünde belirlenmesine çalışılmış, bunun içinde karar destek yöntemi ile kontrollü sınıflandırma yapılmıştır. Bu makale, daha önce yayınlanmış (Kaynarca, Demir, \& San, 2019) 'nın genişletilmiş bir versiyonudur.

\section{YÖNTEM}

\section{1. Çalışma Alanı}

Çalıșma alanı Antalya ili sınırlarında merkezdeki traverten jeolojik formasyonun kapladığı alan olarak seçilmiştir. $\mathrm{Bu}$ alan Döşemealtı, Muratpaşa, Kepez ve Konyaaltı ilçelerinin bir bölümünü içerir. Çalıșma alanının ülkemizdeki konumu Şekil 1'de gösterilmektedir.
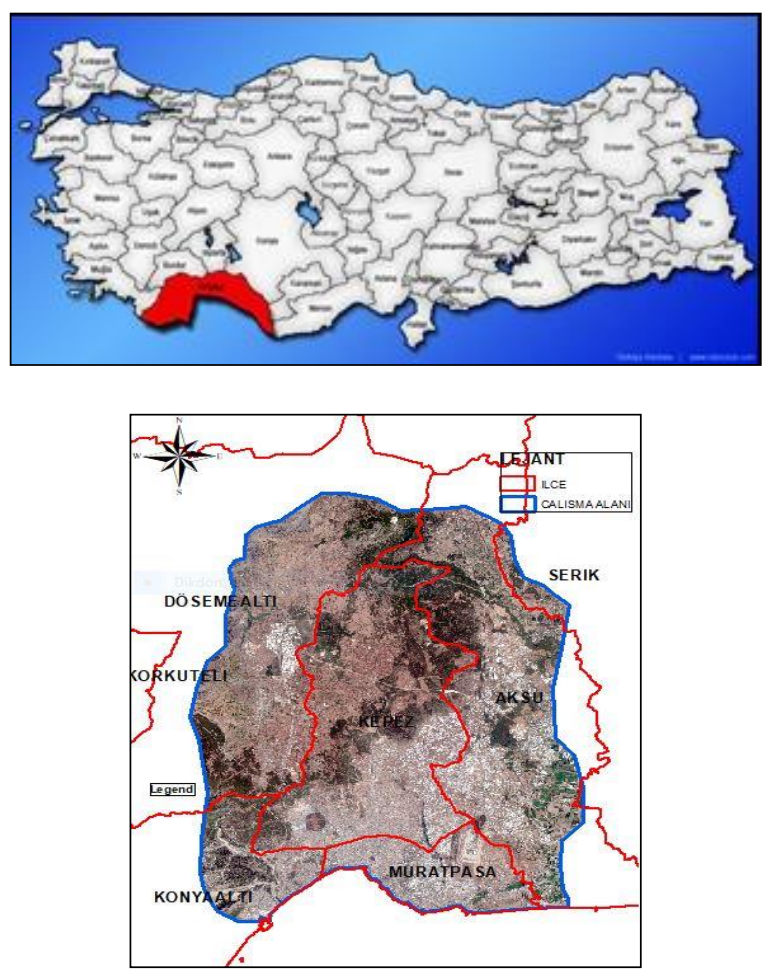

Şekil 1. Çalışma alanı

\subsection{Materyal}

Bu çalışmada kullanılan veriler; Devlet Su İşleri ve Antalya $\mathrm{Su}$ ve Atık $\mathrm{Su}$ İdaresi Genel Müdürlügü'nden kuyulara ait statik, dinamik seviye, verim ve koordinat verilerini içeren MSExcel tabloları alınmıştır. Ayrıca Maden Tetkik ve Arama 
Genel Müdürlüğü'ne ait 1/100 000 ölçekli jeoloji haritaları Sentinel 2 çok bantlı uydu görüntüsünün 2., 3., 4. ,8. bantları (Mavi, Yeşil, Kırmızı, Yakın Kızıötesi) ve Aster Global Digital Elevation Model (GDEM) sayısal arazi modeli kullanılmıştır.

Yapılan bu çalışmada ENVI görüntü işleme ve analiz işlemleri için ENVI, ArcGIS ve MapInfo CBS yazılımlarından faydalanılmıştır.

\subsection{Yöntem}

Calıșmada yapılanlar temel ișlem adımları şematik olarak Şekil 2'de gösterilmektedir. Çalışmada Devlet $\mathrm{Su}$ İşleri (DSI) Genel Müdürlügü'ne ait kuyu verileri Excel tablosunda alınarak CBS ortamına aktarılmış, kuyu verileri MTA'nın Jeoloji haritası üzerine eklenmiş ve traverten olan formasyon dikkate alınarak çalıșma alanı belirlenmiştir. Çalışma alanına giren bölümdeki kuyu verileri ayrılmıştır. Çalışma alanı sayısal arazi modeli ASTER SYM verisi ile yükseklik, eğim haritaları olușturulmuştur.

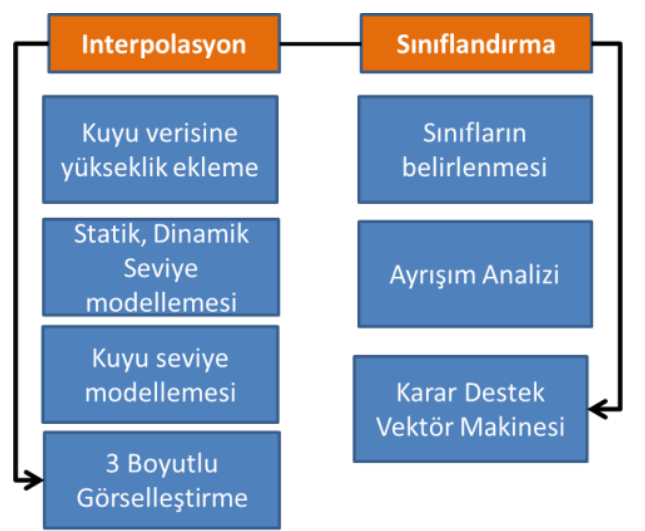

Şekil 2. İşlem adımları

Interpolasyonla değeri bilinmeyen alanlar, bilinen değerlerin kullanılmasıyla tahmin edilir ve yüzeyin temsili sağlanır. Çalışmada yeraltı suyunun statik, dinamik seviyelerini temsil etmesi için model olușturulması için kriging interpolasyon ișlemi yapılmıştır. CBS ve uzaktan algılama birçok alanda yazılımlar kullanarak karar destek sistemlerini desteklemektedir (Taylan, 2016). Çalışmada 1067 adet kuyuya ait kot verilerinden statik ve dinamik seviyeler tablosunda çıkarılmış ve statik ve dinamik su seviyesi kotu hesaplanmıştır. Daha sonra kriging yöntemi kullanılarak çalışma alanına ait statik ve dinamik seviye haritaları üretilmiştir.

UA ve CBS de üç boyutlu modelleme ile çeşitli arazi plan ve yapı modelleri oluşturulmaktadır. $\mathrm{Bu}$ hem görsel hem de kavramsal olarak bilginin daha iyi anlaşılmasına olanak sağlamaktadır. Çalışmada da elde edilen arazi, statik ve dinamik su seviyeleri modellerinin 3 boyutlu görselleştirilmesi yapılmıştır. Oluşturulan 3 boyutlu modelde sayısal arazi modeli, su seviyeleri modelleri ve kuyu verileri kullanılmıştır.
Görüntü sınıflandırma ile görüntü pikselleri bir adet sinıfa atanmaktadır (Ayhan vd. 2003). Çalışmada kontrollü/eğitimli sınıflandırma yöntemi uygulanmıştır. $\mathrm{Bu}$ yöntemde önceden belirlenen sınıf ve eğitim setleri ile sınıflandırma yapılmıştır. Çalışma alanının sınıflandırılmasında yedi ayrı sınıf değerlendirilmiş ve destek vektör makinesi(SVM) yöntemi ile sınıflandırma yapılmıştır. Belirlenen sınıflar orman, su, yerleşim, bitki, sera, ticari alan ve boş alandır. Son yıllarda birçok sınıflandırma ve örüntü tanıma probleminde destek vektör makineleri yöntemi kullanılmaktadır (Kavzoğlu, T.Çölkesen, İ.; Şahin 2015). Sinıflandırma da Sentinel 2 çok bantlı görüntü üzerinden eğitim setleri belirlenmiş, spektral ayrım değerlerine bakılarak sınıfların birbirine hangi oranda karıștığı hesaplanmıştır. Yöntem olarak Jeffries-Matusita, Transformed Divergence kullanılmıștır.

$\mathrm{Bu}$ işlemin ardından çalışma bölgesinin Sentinel 2 çok bantlı uydu görüntüsü kullanılarak destek vektör makinesi (SVM) ile sinıflandırma gerçekleștirilmiştir.

Çalışma alanına göre kuyuların dağılımı ve sayısal yükseklik modeli Şekil 3'te gösterilmiştir.

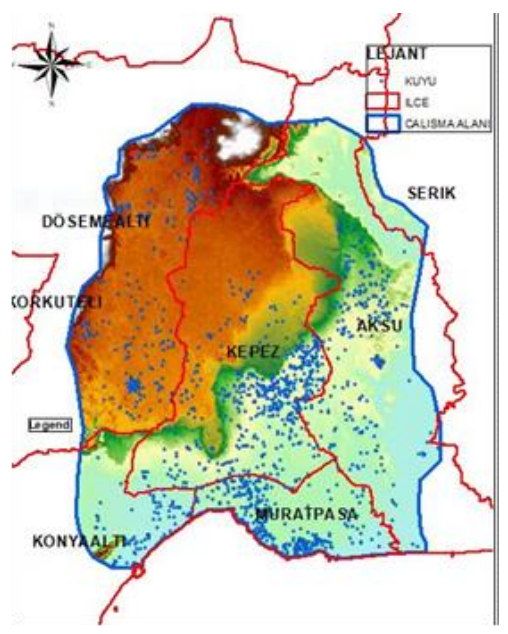

Şekil 3. Sayısal yükseklik modeli ve kuyular

\section{BULGULAR}

Çalışmada 1067 adet kuyu verisi kullanılarak oluşturulan statik ve dinamik yeraltı suyu modelleri ile referans verideki gerçek değerlerin farkları hesaplanmıştır. Fark değerlerinin ortalaması 2.33 ve 2.64 standart sapma değerleri ise 3.69 ve 4.69 olarak hesaplanmıştır.

Çalışmada üretilen bu haritalardan statik yeraltı su seviyesi Şekil 4'de gösterilmektedir. 


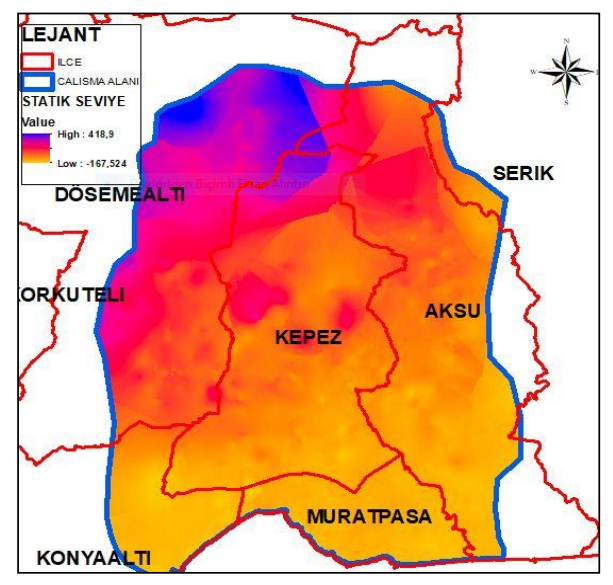

Şekil 4. Statik yeraltı su seviyesi haritası

Standart sapmanın sıfıra yakın değerde olması farkların bu değere yakın olduğunu göstermektedir. $\mathrm{Bu}$ sonuçlara göre üretilen modeldeki değerlerin referans değerlere yakın olduğu anlaşılmaktadır.

Şekil 5'de sayısal yükseklik modelinin 3 boyutlu görseli yer almaktadır. Bu çalışmada verilerin görselleştirilmesi ArcGIS araçları kullanılarak gerçekleştirilmiştir. Çok bantlı uydu görüntüsü oluşturulan 3 boyutlu model de Şekil 6'da gösterilmiştir.

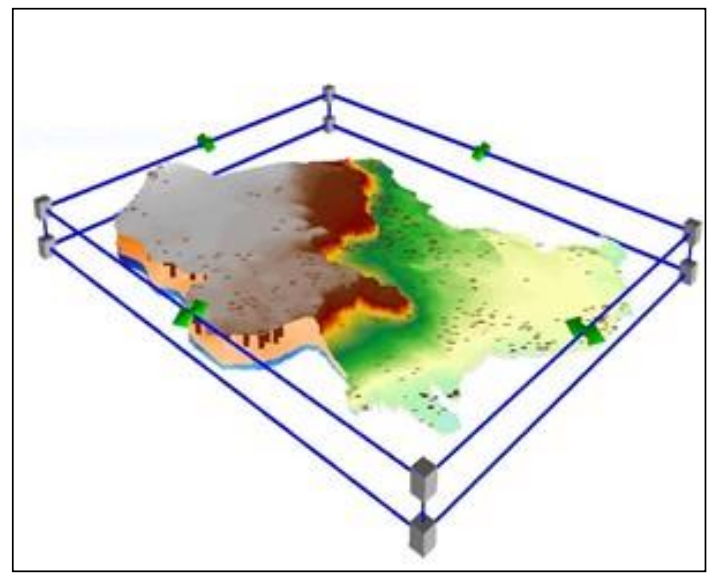

Şekil 5. Sayısal arazi modeli 3 boyutlu görseli

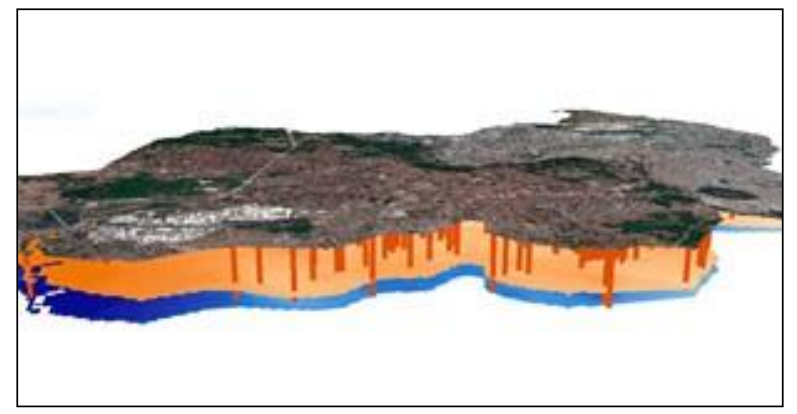

Şekil 6. Çok bantlı uydu görüntüsü 3 boyutlu görseli

Şekil 7'de sınıflandırma sonucu görülmektedir. Sınıflarıma işlemi yapıldıktan sonra morfoloji opening/closing filtresi uygulanmıştır. Bu işlem ile sınıflandırma ile elde edilen görüntü zenginleştirilmiştir.

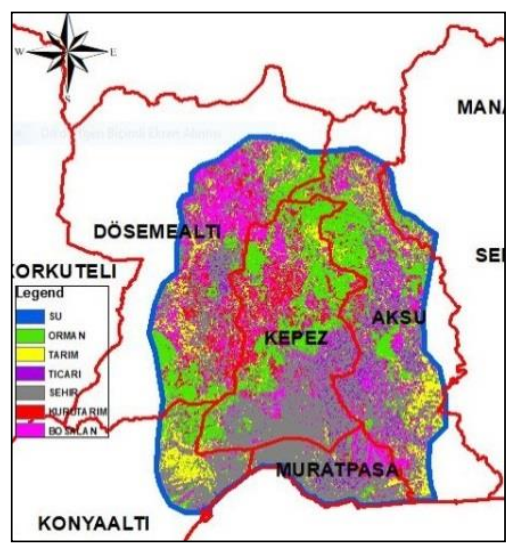

Şekil 7. Sınıflandırma sonucu

Ayrıca çalışmada alanında yapılan sınıflandırma işlemi ile üretilen yedi arazi sınıfının alansal dağılımı Tablo 1'de gösterilmiștir.

Tablo 1. Sınıflandırmanın alansal dağılımı

\begin{tabular}{|l|c|}
\hline Sinif & Alan $^{\mathbf{2}}$ \\
\hline Orman & $143.502 .360,44$ \\
\hline Yerleșim & $188.975 .752,48$ \\
\hline Sera & $22.882 .592,72$ \\
\hline Ticari & $4.660 .798,28$ \\
\hline Boșalan & $125.006 .198,52$ \\
\hline Su & $125.067,28$ \\
\hline Bitki & $26.106 .478,68$ \\
\hline Toplam & $\mathbf{5 1 1 . 2 5 9 . 2 4 8 , 4 0}$ \\
\hline
\end{tabular}

Çalışmada iki farklı doğruluk analizi yapılmıştır. Bunlar üretilen statik ve dinamik seviye modelleri ve sınıflandırma sonuçları için yapılan doğruluk analizleridir. Çalış̧mada kullanılan 1067 adet kuyudan statik ve dinamik seviyeleri ile modelden çıkarılan değerler kuyu tablosuna yazılmıștır. Bu ișlemin ardından gerçek statik ve dinamik su kotu değerleri ile modelden üretilen değerlerin farkları alınarak bazı istatiksel sonuçlar elde edilmiştir. $\mathrm{Bu}$ değerlere ilişkin yapılan hesaplamalar Tablo 2'de gösterilmektedir.

Tablo 2. Model doğrulaması için istatiksel hesaplamalar.

\begin{tabular}{|c|r|c|c|c|c|}
\hline Tablo & Min. & Maks. & Top. & Ort. & $\begin{array}{c}\text { Std. } \\
\text { Sap. }\end{array}$ \\
\hline Statik & 0 & 49 & 2487 & 2.33 & 3.96 \\
\hline Dinamik & 0 & 50 & 2816 & 2.64 & 4.69 \\
\hline
\end{tabular}

Çalışmada yapılan sınıflandırma için yapılan doğruluk analiz sonuçları değerlendirilmiş olup toplam 25935 adet piksel doğruluk analizi için kullanılmış olup bunun alansal karşsllı̆ı 2.593 .500 $\mathrm{m}^{2}$ ' dir. Kappa değeri 0.955, Doğruluk yüzdesi \%96.76 olarak hesaplanmıștır.

\section{SONUÇLAR}

Sonuç olarak çalışmanın hedefi olan yeraltı suyu modeli düşük standart sapma ile çıarılmış ve 
bu alandaki arazi örtüsünün yüksek doğrulukta üretildiği elde edilen doğruluk değerlerine göre oldukça bașarılıdır. Uygulanan yöntemler Antalya ilinde yer alan diğer havzalar için de gerçekleștirilecek şekildedir. Çalışma hayati öneme sahip yeraltı suyu kaynakları ilgili bir model üretmekte, yapılan kontrollü sinıflandırma ile yüzeyde arazi örtüsü ve kullanımı ile modelin korelasyonu sağlanmaktadır. Çalıșmada elde edilen sonuçlarla ve üretilen veri setleri ile yeraltı suyuna ilişkin risk faktörleri en uygun alan tespit vb. çalışmalar içinde temel altlık niteliğinde olabileceği düşünülmektedir.

Çalışmanın yerel yönetimlerin, kamunun ve özel sektörün yeraltı suyu arama ve kullanma ile ilgili çalışmalarda da kullanabilecek ve planlama çalışmalarında orta ölçekte veri kaynağı olacaktır.

Ayrıca sürekli veri akıșının sağlanması ile üretilecek anlık model üretim işlemenin yeraltı suyu seviyesinin sürekli takibi mümkün olabilecektir.

\section{KAYNAKÇA}

Anonymous. (2018). DSİ Su Kaynakları Verileri. Retrieved October 19, 2019, from http://www.dsi.gov.tr/docs/resmiistatistikler-2017/dsi_metaveri_14-122018.doc?sfvrsn=2

Ayhan, E., Karsli, F., ve Tunc Gormus, E. (2003). Uzaktan Algılanmış Görüntülerde Sınıflandırma Ve Analiz. Harita Dergisi, 70, 32-46.

Çelik, R. (2017). Harran Ovası'nın yeraltısuyu potansiyelinin coğrafi bilgi sistemi ile modellenmesi. Dicle Üniversitesi Mühendislik Fakültesi Dergisi, 8, 53-64.

Demir N., Sönmez N.K., Akar T., ve Ünal S., (2018) Automated Measurement of Plant Height of Wheat Genotypes Using a DSM Derived from UAV Imagery, MDPI Proceedings(2) , 350-350.

Erener, A., ve Sarp, G. (2017). Barajların Çevresel Etkilerinin Zamansal Ve Mekansal Olarak Uzaktan Algilama İle Değerlendirilmesi: Atatürk Barajı Örneği. Geomatik 2(1), 1-10. https://doi.org/10.29128/geomatik.300012.

Hökelekli, E. ., ve Yllmaz, İ. (2010). Akarçay Kuzey Alt Havzası Yeraltı Suyu Modellemesi. Afyon Kocatepe Üniversitesi Fen Ve Mühendislik Bilimleri Dergisi, 10(2), 5-16.

Kavzoğlu, T.;Çölkesen, ve İ.;Şahin, E. K. (2015). Obje Tabanlı Yaklaşımda Makine Öğrenme Algoritmalarının Sinıflandırma Performansının Analizi. In TUFUAB VIII. Teknik Sempozyumu (pp. 344-349).
Kaynarca M., Demir N. (2017). Nesne Tabanlı Sinıflandırma İle Karayolunda Bulunan Araçların Tespiti, Afyon Kocatepe Üniversitesi Fen ve Mühendislik Bilimleri Dergisi, Özel Sayı, 12-17.

Kaynarca, M., Demir, N., \& San, B. T. (2019). Antalya İli Yeraltısuyu Kaynaklarının Uzaktan Algılama Ve Coğrafi Bilgi Sistemleri Teknikleri Kullanarak Modellenmesi Ve Arazi Özelliğinin Belirlenmesi. In TUFUAB X. Teknik Sempozyumu (p. 43).

Kunianski, E. L. (2016). Simulating Groundwater Flow in Karst Aquifers with Distributed Parameter Models-Comparison of PorousEquivalent Media and Hybrid Flow Approaches. U.S. Geological Survey. https://doi.org/0.3133/sir20165116

Orhan, O., Kırtıloğlu, O. S., \& Yakar, M. (2020). Konya Kapalı Havzası Obruk Envanter Bilgi Sisteminin Oluşturulması. Geomatik, 5(2), 81-90. https://doi.org/10.29128/geomatik.577167

Polemio, M. (2016). Monitoring and management of karstic coastal groundwater in a changing environment (Southern Italy): A review of a regional experience. Water (Switzerland). https://doi.org/10.3390/w8040148

San, B. T., ve Ulusar, U. D. (2018). An approach for prediction of shoreline with spatial uncertainty mapping (SLiP-SUM). International Journal of Applied Earth Observation and Geoinformation.

https://doi.org/10.1016/j.jag.2018.08.005

Selim S., Demir N. (2018). Analysis of landscape patterns and connectıvity between tree clusters derived from LIDAR data, Fresenius Environmental Bulletin (27), 3512-3520. 